\title{
Correction to: Regulating the San Francisco Sound: How a Music Venue Crackdown Inspired Pioneering Advancements in Entertainment Regulation and Support
}

\author{
Jocelyn Kane, Alicia Scholer, and Ben Van Houten
}

\section{Correction to:}

Chapter 8 in: C. Ballico, A. Watson (eds.), Music Cities, New Directions in Cultural Policy Research, https://doi.org/10.1007/978-3-030-35872-3_8

The original version of the chapter was revised: The footnotes and corresponding footnote numbers cited in Chapter 8 have been removed. 